\title{
Triaxial Test on Clay with Vertical Reinforcement
}

\author{
Ying $\mathrm{Nie}^{1,2, a}$,Yanjun $\mathrm{Li}^{3, \mathrm{~b}}$,Fenghan $\mathrm{Hu}^{1,2, \mathrm{c}}$, Tao Wang ${ }^{3, \mathrm{~d}}$ \\ Xiaofeng Zhao ${ }^{1,2, e}$ and Ningyu Zhao ${ }^{3, f}$
}

1. CISDI Research \& Development Co. Ltd., Chongqing 401133, P.R. China

2. CISDI Architectural Design \& Research Institute, Chongqing 401133, P.R. China

3. School of Civil Engineering, Chongqing Jiaotong University, Chongqing 400074, P.R. China

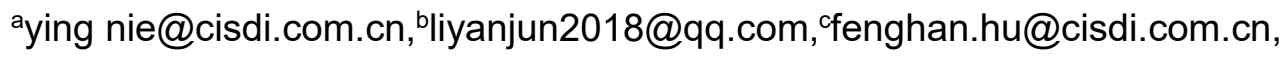

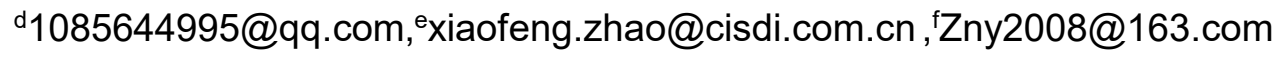

\begin{abstract}
Keywords: clay; vertical reinforcement; triaxial test; strength characteristics
Abstract.A unconsolidated-undrained triaxial test of vertically reinforced clay was carried out. Fiberglass geogrid was used as reinforced material in the form of centrally symmetrical arrangement. The stress-strain relationship, strength characteristics and failure modes of reinforced clay were studied. The effects of different reinforced diameters, different height of vertical bars and different confining pressures on the strength of reinforced clay were discussed. The results showed that the vertical reinforcement has played a role in the performance of the reinforcement from the beginning and greatly improved the shear strength of the soil. The installation of the vertical reinforcement has a significant effect on the reinforcement effect, and there is an optimal form of reinforcement.
\end{abstract}

\section{Introduction}

Reinforced soil is widely used in all areas of civil engineering with the formation of reinforced concrete and soil complex. The addition of the reinforcement changes the stress-strain field of the soil and improves the deformation condition of the soil, thus improving the engineering performance of the soil. With the development and application of new geosynthetics, it is a new trend to study the performance of geosynthetics.

Hongwei Wei et $\mathrm{al}^{[1]}$ used reinforced material with geotextile and geotextile for the unsaturated sample of the consolidated drainage test, pointed out that there was a hysteresis in the improvement of the strength of the soil with horizontal reinforcement.Chenggang Bao et al ${ }^{[2]}$ studied the working mechanism of reinforced soil with unconfined and consolidated undrained test, analyzed the interfacial characteristics between the reinforcement and the soil. The study showed that the friction resisted the lateral deformation of the soil, and the interface changed stress station on both sides of soil within a certain range. Xiaofeng Zhou et $\mathrm{a}^{[3]}$ has studied reinforced sand with dry sand samples on different forms of geogrid. The results show that multi-geogrid reinforced soil strength improved the effect most obviously. However, these reinforcement methods are based on the horizontal reinforcement.

As for the new vertical reinforcement, domestic and foreign research results are relatively a little. Weijian Zhuang ${ }^{[4]}$ put forward the "reinforced ring" in the form of cloth for the first time. The annular material blocked the lateral pressure from the outside to inside of the ring, making the strengthen ring to bear the lateral pressure.Xiequn Wang ${ }^{[5]}$ used the expansive soil as the object for the comparative test in full height of the vertical reinforcement and horizontal reinforcement. The results showed that 
the increase of cohesion is better than that of the traditional horizontal reinforcement. Mengxi Zhang et $\mathrm{al}^{[6-8]}$ proposed the $\mathrm{H}-\mathrm{V}$ (horizontal-vertical) three-dimensional reinforcement concept in conjunction with the traditional reinforcement method. On the basis of the horizontal reinforcement, the influence of different height of height on the strength characteristics of soil is discussed. There are also scholars ${ }^{[9,10]}$ carried out triaxial test in different forms of reinforcement with geocell for stiffened materials.

In a word, this new reinforcement type of the "reinforced ring" was studied rarely. In this paper, the fiberglass geogrid in the form of center symmetrical vertical bar was used as the reinforcement material in the unconsolidated-undrained test. The influence of different "stiffened ring" dimensions (reinforcement diameter, stiffening height and reinforcement layer) on stress-strain characteristics and shear strength parameters were analyzed in order to find the most reasonable reinforcement form.

\section{Testing Scheme}

Test Materials. The soil samples selected from the samples are typically filling materials in Chongqing, which are generally reddish-brown. The physical properties of the soil are determined according to the Test Methods of Soil for Highway Engineering as Table.1. Due to the limitation of the size of the triaxial specimen, the EGA1 $(50 \times 50)$ fiberglass geogrid is used as the test material, and the mechanical properties are as follows: Glass Fiber Geogrid by the tensile test, the results shown in Table 2 .

Table 1 Physical properties of clay

\begin{tabular}{|c|c|c|c|c|c|c|c|c|}
\hline $\begin{array}{l}\text { Proportion } \\
\qquad \mathrm{Gs}_{\mathrm{s}}\end{array}$ & \multicolumn{3}{|c|}{$\begin{array}{l}\text { Maximum dry density } \\
\rho_{\mathrm{dmax}} / \mathrm{g} \cdot \mathrm{cm}^{-3}\end{array}$} & \multicolumn{2}{|c|}{$\begin{array}{l}\text { Optimum moisture content } \\
\qquad \omega / \%\end{array}$} & \multicolumn{2}{|c|}{ Liquid limit } & Plastic limit \\
\hline 2.72 & \multicolumn{3}{|c|}{2.04} & \multicolumn{2}{|r|}{10.6} & 32.5 & \multicolumn{2}{|c|}{17.3} \\
\hline \multicolumn{9}{|c|}{ Table 2 Tensile test results of reinforced materials } \\
\hline \multirow{2}{*}{ specification } & \multicolumn{2}{|c|}{ Mesh size /mm } & \multicolumn{2}{|c|}{ Mesh amount } & \multicolumn{2}{|c|}{ Breaking strength $/ \mathrm{kN} \cdot \mathrm{m}^{-1}$} & \multicolumn{2}{|c|}{ Elongation at break $/ \%$} \\
\hline & Warp & Weft & Warp & Weft & Warp & Weft & Warp & Weft \\
\hline EGA1 $(50 \times 50)$ & 20 & 20 & 1 & 1 & 57.1 & 54.4 & 2.49 & 1.46 \\
\hline
\end{tabular}

Preparation of the Sample. The sample was made in the best moisture content of $10.6 \%$. Because the changes of the soil strength to the moisture content are sensitive ${ }^{[11,12]}$, the sample was mothballed with plastic wrap after added water and mixed well, and put into the conservation equipment for 24 hours after the sample preparation in order to ensure the uniformity of the sample moisture content and stability.

The literature ${ }^{[1]}$ shows that reinforced specimen with high compactness tended to be dilatancy, the lateral deformation of the specimen by the constraints of the material is conducive to play the high tensile strength of the characteristics. So in the study, the test compaction degree was $93 \%$ and the sample dry density was $1.90 \mathrm{~g} / \mathrm{cm}^{3}$.

The triaxial specimen has a height of $20 \mathrm{~cm}$ and a diameter of $10 \mathrm{~cm}$. The fiberglass grating was cut into strips, and was made into different diameter and height of the ring with the adhesive. The ribs are placed hierarchically in the center of the specimen, and the vertical spacing between the tendons was controlled at $2 \mathrm{~cm}$, as shown in Fig. 1. As the fiberglass grating texture is soft, coupled with the specific form of vertical reinforcement, the reinforcement into the soil to achieve the ideal state of Fig. 1 is much difficult. Refer to the relevant literature ${ }^{[5]}$, the sample was buried in the vertical reinforcement in the way of hollow. The middle of the soil sample was hollowed out with the custom diameter of the cylinder, then put the preformed good ring into sample, lastly compacted the sample 
in the ring with corresponding diameter of the hammer. When placing the tendons, the soil was properly shaved and the friction between the soil and the tendons would be increased.

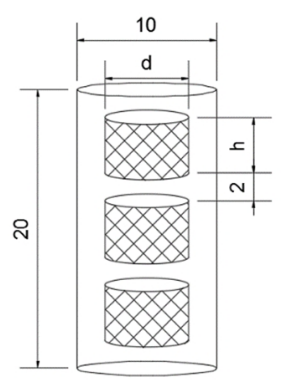

Fig. 1 Schematic diagram of three layer reinforcement (unit: $\mathbf{c m}$ )

Test Plan.The British GDS triaxial tester was used in this test, as the matching GDSLAB number of mining system can achieve the automatic collection of test data and storage. The strain rate was $1.5 \mathrm{~mm} / \mathrm{min}$ in the test, and 100, 200 and $300 \mathrm{kPa}$ confining pressures were selected to draw the complete strength envelope. The peak value of the principal stress difference was used as failure point to draw the stress-strain curve while $15 \%$ axial strain was determined as the failure point if there was no peak value. The detailed test method refers to the 《Highway Geotechnical Test Procedure》(JTG E40-2007).

According to the "reinforced ring" diameter and height of the different, five kinds of conditions was designed as Table 3. Case 1 is a soil sample without reinforcement. Condition $2 \sim 4$ evenly arranged 3 layers of reinforcement in the form of the center of symmetry, aiming to compare the reinforcement effect of different diameter in the reinforcement. Condition 5 and Condition 3 have the same reinforcement ratio to compare the effects of different stiffening and stiffening layers on soil strength. Each condition was tested respectively at confining pressures of 100, 200 and $300 \mathrm{kPa}$ to obtain their stress-strain law. In order to improve the accuracy of the test, three groups of parallel test in each conditions was done to take its valid data.

Table 3 vertical three-dimensional reinforced test conditions

\begin{tabular}{cccc}
\hline \multirow{2}{*}{ condition } & $\begin{array}{c}\text { Reinforcement diameter } \\
\mathrm{d} / \mathrm{cm}\end{array}$ & $\begin{array}{c}\text { Vertical bar height } \\
\mathrm{h} / \mathrm{cm}\end{array}$ & $\begin{array}{c}\text { Number of reinforcement layers } \\
\text { M1 }\end{array} 0^{\text {M2 }}$ \\
M3 & 4 & 0 & 0 \\
M4 & 6 & 4 & 3 \\
M5 & 8 & 4 & 3 \\
\hline
\end{tabular}

\section{Test Results and Analysis}

Stress-Strain Curve Characteristics.The stress-strain curves of the three-axis test of vertical reinforced soil are shown in Fig. 2 (limited to length, only 200 and $300 \mathrm{kPa}$ stress-strain maps are given). It can be seen from the figure that the stress-strain trend of the reinforced soil is similar to that of the soil, which is basically hyperbolic. The peak value of the stress-strain curve is between $2 \%$ and $4 \%$ of the axial strain. After reinforcement, both the peak strength and the residual strength of the soil were improved. 


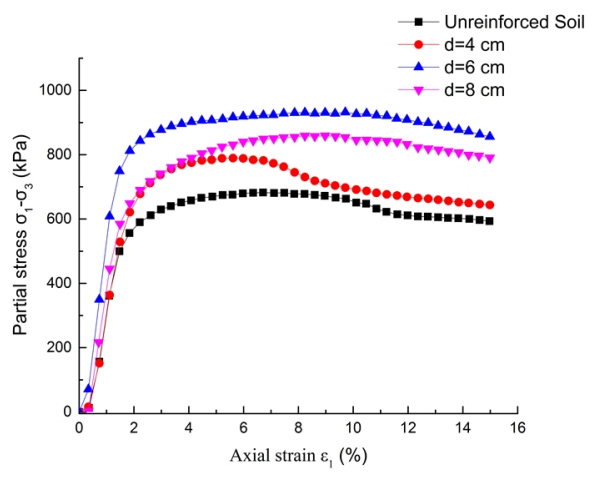

(a)confining pressure $200 \mathrm{kPa}$

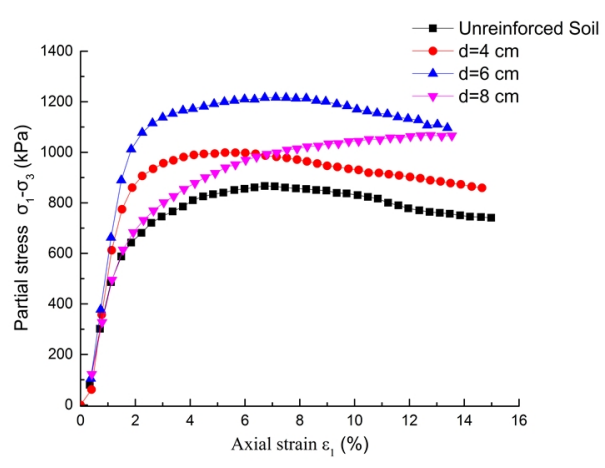

(b)confining pressure $300 \mathrm{kPa}$

Fig.2 Stress-strain curves of different stiffened diameters

Hongwei Wei ${ }^{[1]}$ found that in the axial strain is low, the reinforced soil strength in the form of horizontally reinforcement grew behind the original soil. However, the experimental results showed that the deviation stress of the reinforced soil is always higher than that of the soil, and there is no hysteresis. The reinforcement has restricted the lateral deformation of the soil from the beginning, because the method of hole-backfill sample preparation in this test made a local compaction area. The area gave a prestress to reinforcement at the beginning. The reinforcement grew deformation while it was strechted, which produced some constraints to the surrounding soil of the ring. Thus the material does not need a certain deformation of the soil before they can play its role.

The stress-strain characteristics of soils with reinforced diameters of $6 \mathrm{~cm}$ and $8 \mathrm{~cm}$ are mainly strain hardening while the soils with $4 \mathrm{~cm}$ in diameter showed a certain strain softening phenomenon. After reaching the peak intensity, the deviation stress gradually decreases when the strain gradually increases. The deviation stress of the $4 \mathrm{~cm}$ reinforced soil decreased faster than that of the soil. The experimental results showed that the reinforcement effect does not increase continuously with the increase of diameter, and there is an optimal reinforcement diameter. The vertical reinforcement effect can not be fully exploited when diameter is higher than this limit. From the results of the test, it is concluded that this optimum diameter should be $6 \mathrm{~cm}$.

According to the above test results, the condition 5 was designed to studied the effect of different reinforcement heights and reinforcement layers on the strength of reinforced soil. In the case of working condition 3, the height of the vertical bar is increased by $2 \mathrm{~cm}$, and a layer was decreased, so that the working conditions 5 and the working conditions 3 have the same reinforcement ratio.and the stress-strain curve was showed as Fig. 3.

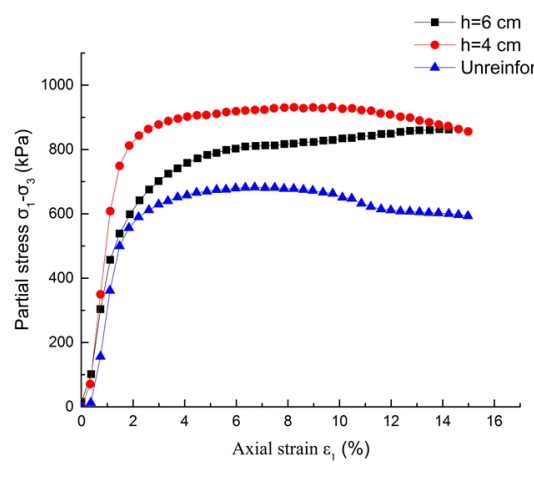

(a)confining pressure $200 \mathrm{kPa}$

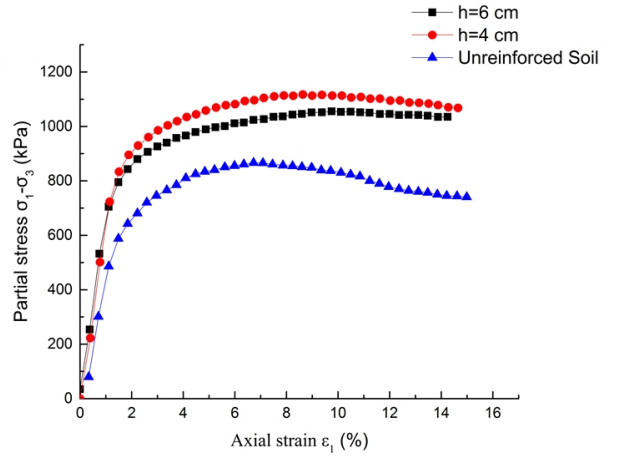

(b)confining pressure $300 \mathrm{kPa}$

Fig. 3 different stiffening stress-strain curves

The stress-strain characteristics and trends of different reinforced specimens are consistent with those described above, and their peak intensity and residual strength are greatly increased compared 
with those of the soil. The stress-strain characteristics also show strain hardening. Under the same reinforcement ratio, the height of the vertical bar $h=4 \mathrm{~cm}$ with the reinforcement of the three-layer cloth was better than that of the vertical bar height $\mathrm{h}=6 \mathrm{~cm}$ with two- layer cloth.

Shear Strength Index of Reinforced Soil.According to the triaxial test results of reinforced soil, the triaxial test data were processed by electronic form method ${ }^{[13]}$, and the shear strength index of reinforced soil was calculated shown as Table 4.

In order to evaluate the strength of the reinforced soil after the reinforcement, the reinforcement effect coefficient $\mathrm{R}^{[14]}$ is introduced. According to the for Eq. 1, the reinforcement effect coefficient under various working conditions was shown in Table 4.

$$
R=\frac{\left(\sigma_{1}-\sigma_{3}\right)_{\mathrm{f}}^{\mathrm{R}}}{\left(\sigma_{1}-\sigma_{3}\right)_{\mathrm{f}}}
$$

In the formula: R: the strength reinforcement effect factor;

$\left(\sigma_{1}-\sigma_{3}\right)_{f}^{R}:$ the main stress difference when the reinforced soil is damaged;

$\left(\sigma_{1}-\sigma_{3}\right)_{f}:$ the main stress difference when there is no soil damage.

Table 4 under different conditions of strength index and reinforcement effect coefficient

\begin{tabular}{cccccc}
\hline & \multicolumn{2}{c}{ Shear strength index } & \multicolumn{2}{c}{$\begin{array}{c}\text { the reinforcement effect coefficient under different } \\
\text { confining pressure }(\mathrm{kPa})\end{array}$} \\
\cline { 2 - 6 } conditions & $\begin{array}{c}\text { Internal } \\
\text { Cohesion } \\
\mathrm{c} / \mathrm{kPa}\end{array}$ & $\begin{array}{c}\text { friction angle } \\
\varphi /{ }^{\circ}\end{array}$ & 100 & 200 & 300 \\
\hline M1 & 76.4 & 29.2 & 1 & 1 & 1 \\
M2 & 81.5 & 32.8 & 1.158 & 1.157 & 1.153 \\
M3 & 132.5 & 31.5 & 1.498 & 1.366 & 1.291 \\
M4 & 163.7 & 27.2 & 1.466 & 1.259 & 1.233 \\
M5 & 97.0 & 32.9 & 1.278 & 1.265 & 1.219 \\
\hline
\end{tabular}

Table 4 showed:

(1)The vertical reinforcement has a different effect on the soil cohesion $\mathrm{c}$ and the internal friction angle $\varphi$. With the increase of the diameter of the reinforcement, the cohesion increases sharply while the internal friction angle $\varphi$ is limited. The vertical reinforcement had a certain increase on the $c, \varphi$ values, but had greater contribution on c value.

(2)For the same condition of reinforced soil, the reinforcement effect coefficient decreased with the increase of confining pressure. This was similar to the level of reinforced soil, which the greater the confining pressure, the more obvious the effect of reinforcement, and the reinforcement would be better under low confining pressure. In Fig. 3, under the same reinforcement ratio, the reinforcement effect coefficient was reduced with the confining pressure increasing, and the effect of the reinforcement was less. At the same time, the stress-strain curve difference between the working condition 3 and the working condition 5 was less.

(3) Under the same confining pressure, the reinforcement effect coefficient increased firstly then decreased with the increase of the reinforcement diameter. It showed that the "reinforced ring" has an optimal reinforcement diameter. Different diameters of different layers formed different local areas in the"soil-cake", and the "cake" area changed the stress and strain field of the soil, having an impact on the strength characteristics of soil. 
(4) Compared with the reinforcement effect coefficient of the working condition 3 and the working condition 5, the reinforcement of the three layers showed a better reinforcement effect under the same reinforcement ratio. But compared with conditions 3, reinforced effect coefficient changed little with the variety of confining pressure in the working conditions of 5, which means more stable. This showed that the performance of reinforced concrete in the form of 5 is not able to play fully, only part of the material played a role.

The Destroyed Form Soil Samples. Fig. 4 was the shape of specimen after the destruction. the destruction of soil samples was along with the entire rupture surface, and the middle part was of the extrusion-like, which was seriously damaged. The cracked specimen of the reinforced soil specimen was narrower and was not completely penetrated. It was lateral bulging in the middle and lower parts. There are obvious signs of contraction in the reinforced part, showing irregular arc shape, which said that the vertical reinforcement made a great contribution on limit lateral deformation of soil. The specimens were made an incision to observe the shape of the vertical bars after the test. It was found that the ribs at the top layer were not deformed, while the middle and lower layers were mainly inclined and stretched. The soil had a sign of lateral extrusion from the web of the fiberglass geogrid, and the vertical reinforcement does not show a significant traces of damage. This phenomenon was due to the structure of the reinforcement itself-the mesh structure. Another reason may be the higher tensile strength and modulus of the reinforcement. The friction coefficient between the reinforcement and the soil was relatively small, causing relative motion of the reinforcement and soil during the shearing process. In addition, the method of sample preparation is one of the reasons for this phenomenon.

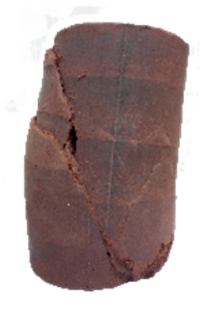

(a) Unreinforced soils

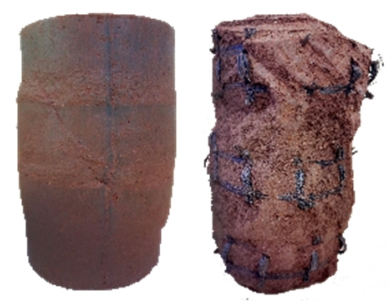

(b) Reinforced soil

Fig. 4 Typical failure pattern of the specimen

\section{Conclusions}

1.When the strain is small, the strength growth rate of the specimen with vertical reinforcement does not appear to lag behind the unreinforced soil, for the reinforcement acts at the beginning.

2. Compared with unreinforced soil, vertical reinforcement forms can enhance the shear strength parameters including cohesion $\mathrm{c}$ and the internal friction angle $\varphi$, but it has a greater contribution to the cohesion $\mathrm{c}$.

3. The vertical reinforcement can effectively restrain the soil lateral deformation, forming a "cake area" in the soil. The cake-shaped area changes stress-strain field of soil, which is the core of the reinforcement effect is better than that of horizontal reinforcement.

4.The increase of the vertical reinforced soil strength does not increase continuously with the diameter of the reinforcement, and there is an optimal reinforcement diameter. meanwhile, the reinforcement height and the number of reinforced layers have significant influence on the effect of reinforcement. According to the results of this triaxial test, Reinforcement diameter of $6 \mathrm{~cm}$, reinforced height of $4 \mathrm{~cm}$ and the three-layer layout is the best reinforcement form. 


\section{Acknowledgments}

The authors are grateful to the Science Program of Chongqing Municipal Commission of UrbanRural Development (No: 2016-0001) and the Foundation of CISDI Research \& Development Co. Ltd.(90270341-KJ-002) for the financial support for this research project.

\section{References}

[1] Hongwei Wei, Zehong Yu, Huawei Yin.Triaxial shear tests on clayey soil reinforce with geosynthetics . Engineering Mechanics. 2007(05):107-113(In Chinese).

[2] Chenggang Bao,Mingyuan Wang,Jinhua Ding.Experimental Study on The Working Mechanism Of Grating Reinforced Soil .Journal of Yangtze River Scientific Research Institute,2013(01):3441(In Chinese).

[3] Xiaofeng Zhou,Mengxi Zhang,Chengchun Qiu,Hong Zhu,Jin Wang,Strength of Sand Reinforced With Different Forms of Geogrid. Journal of Shanghai Jiaotong University,2013(09):13771381(In Chinese).

[4] Weijian Zhuang .Reinforced Earth Retaining Wall New Technology HIGHWAY .2002(In Chinese).

[5] Qunqun Wang,Min Guo,Bo Hu.Triaxial Testing Study of Expansive Soil Reinforced With Geogrid.Rock and Soil Mechanics.2011(06):1649-1653(In Chinese).

[6] Mengxi Zhang,Zhenwu Wang.Strength Properties of Two-Layer Three-Dimensional Reinforced Sand .Rock and Soil Mechanics,2006(S1):3289-3298(In Chinese).

[7] Mengxi Zhang, Xianbo Zhang, Jingjing Duan.Strength And Deformation Properties of H-V Reinforced Clay.Rock and Soil Mechanics,2009,30(6):1563-1568(In Chinese).

[8] Mengxi Zhang, Gaofeng Chen, Yin Zhu,Triaxial Tests on Saturated Sands Reinforced With Horizontal-Vertical Inclusions. Rock and Soil Mechanics.2010,31(5):1345-1351(In Chinese).

[9] Zhuojun Ma, Xingyan Zhang, Zhenong Jia.Study on Strength Characteristics of Reinforced Cohesive Soil in Geocell. Highway.2000(10):34-35(In Chinese).

[10]Rong Zhang.Study On Strength Characteristics of Geocell Reinforced Soil. Railway Engineering.2014(2):76-79(In Chinese).

[11]Linchang Miao, Xiaochen Zhong, Zongze Yin.The Relationship Between The Strength of Expansive Soil and Water Content. Rock and Soil Mechanics.1999(02):71-75(In Chinese).

[12] Wentao Ding, Shengyou Lei.Influence of Water Contents on Strength of Reinforced Expansive Soils. Rock and Soil Mechanics.2007(02):391-394(In Chinese).

[13]Lihong Chen, Songtao Tang, Hongtao Zhang.Excel Method in Triaxial Test Data Processing Journal of Beijing Jiaotong University.2010(01):54-57(In Chinese).

[14]Mengxi Zhang,Xing Min.Triaxial Tests on Sand Reinforced With One-Layer 3d Reinforcement. Chinese Journal Of Geotechnical Engineering.2006(08):931-936(In Chinese). 